\title{
A Dilatancy Relation for OVerconsolidated Clay
}

\author{
Zhiwei Gao ${ }^{1} \dagger$, Jidong Zhao ${ }^{1 *} \&$ Zhen-Yu Yin ${ }^{2}$ \\ ${ }^{1}$ Department of Civil and Environmental Engineering, Hong Kong University of Science and \\ Technology, Clear Water Bay, Kowloon, Hong Kong \\ ${ }^{2}$ UMR CNRS 6183 Research Institute in Civil and Mechancial Engineering, École Centrale Nantes, \\ France
}

\section{Abstract}

A distinct feature of overconsolidated (OC) clays is that their dilatancy behavior is dependent on the degree of overconsolidation. Typically, a heavily OC clay shows volume expansion while a lightly OC clay exhibits volume contraction when subjected to shear. Proper characterization of the stress-dilatancy behavior proves to be important for constitutive modeling of OC clays. This paper presents a dilatancy relation in conjunction with a bounding surface or subloading surface model to simulate the behavior of OC clays. At the same stress ratio, the proposed relation can reasonably capture the relatively more dilative response for clay with higher overconsolidation ratio (OCR). It may recover to the dilatancy relation of modified Cam-clay (MCC) model when the soil becomes normally consolidated (NC). A demonstrative example is shown by integrating the dilatancy relation into a bounding surface model. With only three extra parameters in addition to those in the MCC model, the new model and the proposed dilatancy relation provide good predictions on the behavior of OC clay in comparison with experimental data.

Keywords: Clay; dilatancy; overconsolidation; bounding surface; constitutive model

\section{Introduction}

Naturally deposited clays may exhibit certain degree of overconsolidation due to their past loading history such as cyclic loading, repeated compaction, excavation and refilling, as well as water table variation. A distinct feature of an OC clay is its dilatancy behavior depends closely on the degree of overconsolidation. When

\footnotetext{
*Corresponding author. Fax: 852-2358 1534. Email: jzhao@ust.hk.

$\dagger$ Current address: School of Engineering, University of Glasgow, UK G12 8QQ
} 
subjected to shear, an OC clay shows typically a volume expansion when the OCR is high, and a volume contraction when the OCR is low (Henkel 1956; Herrmann et al. 1981; Gens 1982; Zervoyanis 1982; Shimizu 1982; Yin et al. 2002; Hattab and Yicher 2004; Nakai and Hinokio 2004). Indeed, dilatancy has always been regarded key to the characterization of both strength and deformation of soils (Taylor 1948; Rowe 1962; Bolton 1986; Schofield 1998; Jefferies and Shuttle 2002; Mita et al., 2004; Yin and Chang 2013; Ni et al., 2014; Kimoto et al., 2014). Based on the interlocking concept of Taylor (1948), for example, Schofield (1998) has shown that clay on the dry side of critical state will dilate, and the dilation accounts for the observed difference between the peak and critical state strengths. After the peak, the rate of volume expansion will decrease while the soil gradually approaches the critical state with zero dilatancy.

There have been numerous efforts attempting to address the dilatancy behavior of OC clays, most of which are based upon the original or the modified Cam-clay models (Roscoe and Schofield 1963; Roscoe and Burland 1968). Representative works include the bounding surface or subloading surface models that incorporate the following MCC dilatancy relation (e.g., Yao et al. 2009, 2011)

$$
D_{M C C}=\frac{d \varepsilon_{v}^{p}}{\left|d \varepsilon_{q}^{p}\right|}=\frac{M_{c}^{2}-\eta^{2}}{2 \eta}
$$

where $d \varepsilon_{v}^{p}$ and $d \varepsilon_{q}^{p}$ denote the plastic volumetric and deviatoric strain increments, respectively; $\eta=q / p$ is the stress ratio; $p\left(=\sigma_{i j} \delta_{i j} / 3\right)$ is the mean stress and $q$ $\left[=\sqrt{3\left(\sigma_{i j}-p \delta_{i j}\right)\left(\sigma_{i j}-p \delta_{i j}\right) / 2}\right]$ is the deviatoric stress, with $\sigma_{i j}$ and $\delta_{i j}$ denoting the stress tensor and Kronecker delta, respectively; $M_{c}\left[=6 \sin \varphi_{c} /\left(3-\sin \varphi_{c}\right)\right]$ is the critical state stress ratio in triaxial compression and $\varphi_{c}$ is the critical state friction angle. The dilatancy relation presented in Eq. (1) is known to fail to capture the dilatancy behavior of heavily OC clays. As long as $\eta<M_{c}$, the relation gives rise to plastic volume contraction response, whereas experimental observations indicate that 
heavily OC clays may start to dilate at a stress ratio lower than $M_{c}$ in triaxial compression (see Fig. 1). Eq. (1) tends therefore to underestimate the volume expansion of heavily OC clays in drained shear (Yao et al. 2009) or underestimate the amount of negative pore water pressure generation in undrained shear (Yao et al. 2011). Similar issue may be encountered if a plastic potential function independent of the degree of overconsolidation is employed (see, e.g., Banerjee and Yousif 1986; Nakai and Hinokio 2004). Remedying methods have been proposed to overcome this drawback associated with OC clay modeling. In their bounding surface models, Dafalias and Herrmann (1986) as well as Ling et al. (2002), for example, have chosen a mapping center in the $p$-axis located in between the origin and the apex of the bounding surface (see Fig. 2). Since an associated flow rule is defined on the bounding surface, the predicted dilatancy is smaller (or more dilative) when the OCR is higher at the same stress ratio (Fig. 2). Similar idea has been adopted by Hashiguchi (1980) in dealing with the similarity center for the subloading and normal yield surfaces in their model. Pestana and Whittle (1999) have proposed a non-associated flow rule expressed by a linear interpolation function of the plastic flow at the first yield point and the image stress point on the bounding surface for OC clays. While these approaches have gained more or less success in treating the dilatancy behavior of OC clay in an implicit way, overly complex formulation involving excessive model parameters difficult to calibrate constitutes the main reason that prevents them being widely used for practical application.

Meanwhile, there are also attempts to model clay dilatancy by using the state parameter $\psi\left(=e-e_{c}\right)$ as proposed by Been and Jefferies (1985), where $e$ is the current void ratio and $e_{c}$ is the critical void ratio at the same mean effective stress. For example, Scarpelli et al. (2003) have adopted $\psi$ as a state variable to render the response of an $\mathrm{OC}$ clay more dilative than that of a $\mathrm{NC}$ one at the same stress ratio. Special attention, however, has to be paid to ensure that the two conditions, $\psi=0$ 
and $\eta=M_{c}$, are satisfied simultaneously when the clay reaches the critical state (see, e.g., Li and Dafalias 2000). In their micromechanical model for OC clays, Yin and Chang (2009) have introduced an empirical dilatancy relation in terms of $e / e_{c}$ to account for the effect of overconsolidation. It is yet unclear how the parameters associated with the micro-scale behavior are determined. It is also noticed that Collins and Muhunthan (2003) have also proposed stress-dilatancy relation for soils by assuming that the volume changes are induced by two mechanisms (purely kinematic constraint and direct response to changes in stress) within the modern thermomechanical framework. However, such dilatancy relation can not account for the effect of overconsolidation.

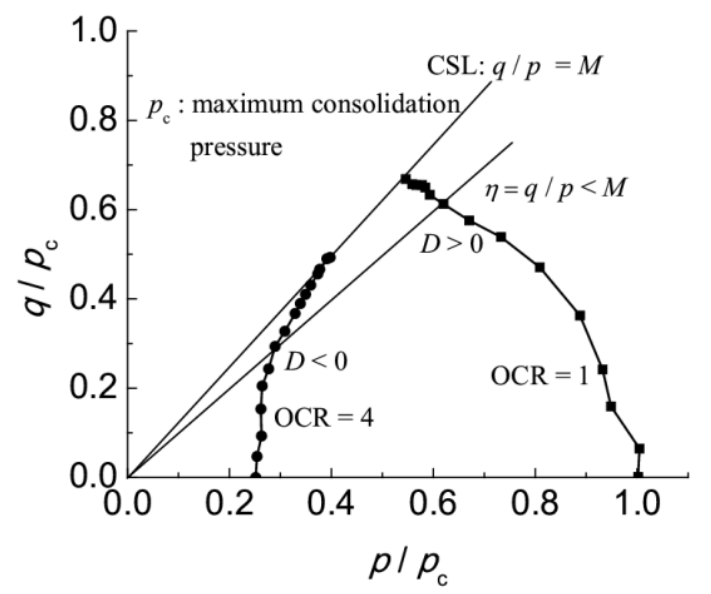

Fig. 1 Typical stress paths for $\mathrm{NC}$ and $\mathrm{OC}$ clays in undrained triaxial compression tests (data from Yin et al. 2002).

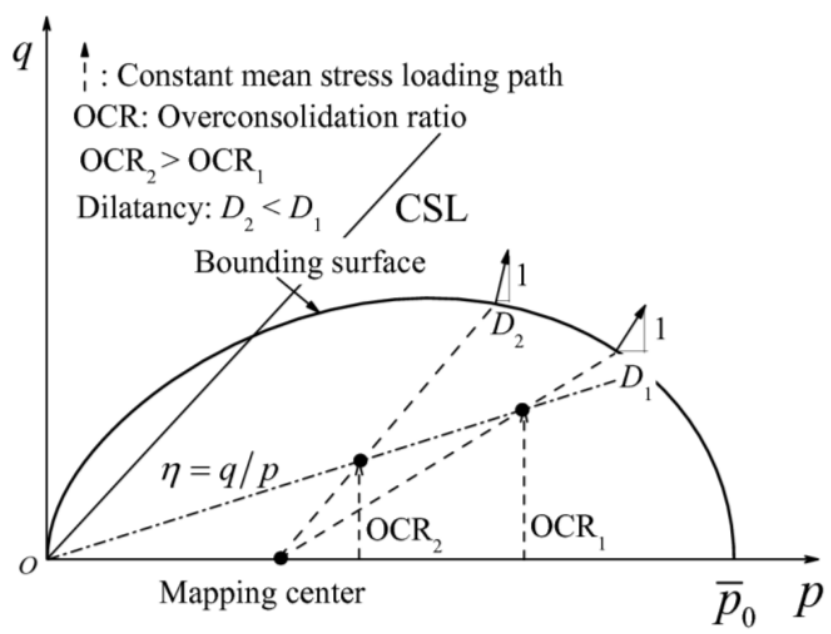

Fig. 2 Illustration of the mapping rule and predicted dilatancy in the bounding surface model proposed by Dafalias and Herrmann (1986). 
In this study, a simple dilatancy relation for OC clay will be proposed based on that in the MCC model as presented in Eq. (1). The new relation is able to account for the effect of loading history on the volumetric response of reconstituted clays and can be easily used in pair of either the bounding surface or the subloading surface models for OC clay. A demonstrative bounding surface model is then developed with the implementation of this dilatancy relation, and its performance and advantage in predicting the behavior of OC clay are illustrated.

\section{A simple dilatancy relation for OC clay}

A suitable variable characterizing the degree of overconsolidation needs to be selected to formulate the dilatancy relation for OC clays. Indeed, in several bounding surface models for OC clays, the ratio $R=r / \bar{r}$ has been used as a key variable to characterize the degree of overconsolidation, where $r$ and $\bar{r}$ denote the distances of the current and image stress point from the mapping center, respectively (see Fig. 3b). Smaller $R$ corresponds to higher degree of overconsolidation. By adopting the origin of the $p-q$ plane as the mapping center, we shall employ this $R$ as a descriptor for the degree of overconsolidation. Essentially, $R$ is the reciprocal of the commonly referred OCR at $q=0$. Based on this definition of $R$, we propose the following dilatancy relation for OC clay

$$
D=\frac{d \varepsilon_{v}^{p}}{\left|d \varepsilon_{q}^{p}\right|}=\frac{M_{d}^{2}-\eta^{2}}{2 \eta}
$$

where

$$
M_{d}=M_{c} R^{m}
$$

where $m$ is a non-negative parameter. Indeed, the dilatancy relation in Eq. (2) can be employed in the subloading surface models as well. In this case, $R$ should be replaced by the ratio of the size of subloading surface to that of the normal yield surface as discussed by Hashiguchi (1980) and Yao et al. (2011). This dilatancy relation has the following features: 
(a) For NC clays with a stress state on the bounding surface (note that OC clays may also become NC as plastic deformation accumulates), $R=1$ and $M_{d}=M_{c}$ (Eq. (3)). In this case, Eq. (2) is recovered to the dilatancy relation of the MCC model in Eq. (1);

(b) As the degree of overconsolidation increases, $R$ decreases, so do $M_{d}$ and $D$ (Eqs. (2) and (3)). This indicates that the response of a clay with higher degree of overconsolidation would be more dilative (or less contractive) at the same stress ratio $\eta$, which is in agreement with experimental observations (e.g., Stipho 1978; Nakai and Hinokio 2004);

(c) At the critical state, the stress state lies on the bounding surface $(R=1)$ with $\eta=M_{c}$, and thus, $D=0$.

\section{A bounding surface model for OC clay}

Based on the dilatancy equation in Eqs. (2) and (3), a simple bounding surface model for OC clay will be developed. Only the model formulations in the triaxial stress space will be presented. The model can be readily generalized to the three-dimensional stress space using the $g(\theta)$ method (e.g., Yin et al. 2013) or the transformed stress method (Yao et al. 2009).

\section{Bounding surface}

The elliptical yield surface of the MCC model has been modified in numerous past studies to achieve better model performance in predicting the undrained shear strength of soils (see, Yu 1998; Pestana and Whittle 1999; Ling et al. 2002; Yin et al. 2002; Collins 2005; Dafalias et al., 2006; Yin and Chang 2009; Jiang and Ling 2010; Yao et al. 2011). We employ herein the $\alpha-\gamma$ yield surface proposed by Collins (2005) as the bounding surface ( $\alpha$ and $\gamma$ are two parameters controlling the shape of the surface) to model the behavior of OC clay. In particular, as will be shown in the subsequent sections, the assumption of $\alpha=\gamma$ is appropriate for a variety of clays, 
which will be adopted here. Specifically, the following function is adopted as the bounding surface in the subsequent discussion

$$
\bar{f}=\frac{\left(\bar{p}-\alpha \bar{p}_{0} / 2\right)^{2}}{\left[(1-\alpha) \bar{p}+\alpha \bar{p}_{0} / 2\right]^{2}}+\frac{\bar{q}^{2}}{M_{c}^{2}\left[(1-\alpha) \bar{p}+\alpha^{2} \bar{p}_{0} / 2\right]^{2}}-1=0
$$

where $\bar{p}_{0}$ denotes the size of the bounding surface (see Fig. 3). For OC clays with an initially isotropic stress state before shear, $\bar{p}_{0}=p_{c}$, where $p_{c}$ is the maximum consolidation pressure ; $\bar{p}$ and $\bar{q}$ are respectively the mean stress and deviatoric stress at the image stress point. Note that a stress quantity with a super bar indicates that it is associated with the bounding surface in this paper. The recommended range of parameter $\alpha$ is 0 to 1.8 which will ensure that the bounding surface stays convex. Eq. (4) is recovered to the MCC yield surface when $\alpha=1$. Fig. 3 shows the variations of shape of the bounding surface with different $\alpha$ and the mapping rule employed here.

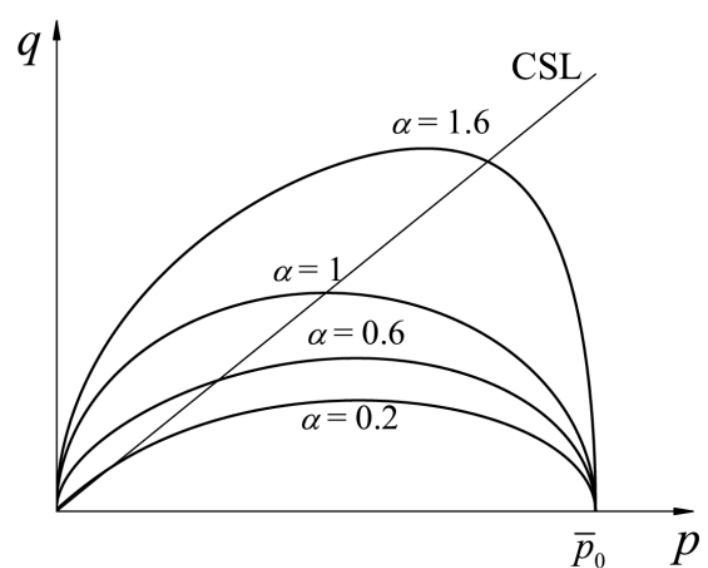

(a)

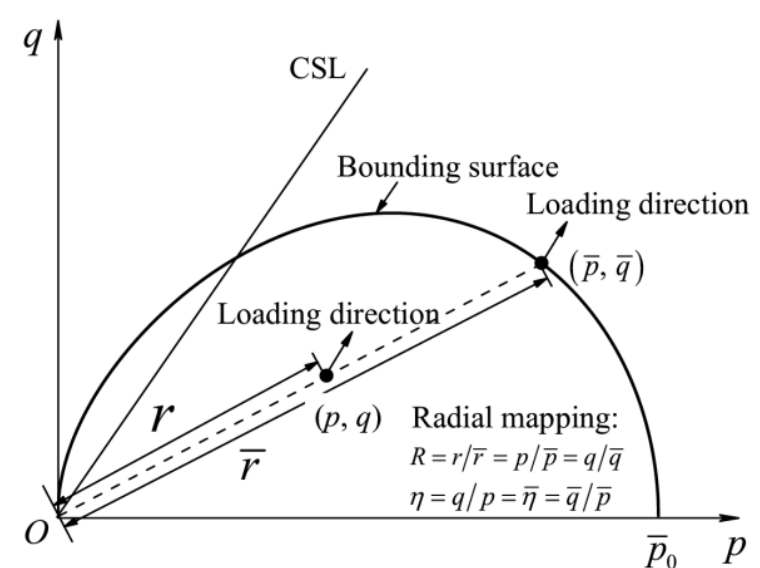

(b)

Fig. 3 (a) Variation of the shape of the bounding surface with different $\alpha$ values, and (b) the radial mapping rule with the mapping center located at the origin of the $p-q$ plane and the definition of $R$.

\section{Plastic modulus}

Following Dafalias and Herrmann (1986) as well as Pestana and Whittle (1999), the same isotropic hardening law as in the MCC model is assumed for $\bar{p}_{0}$,

$$
d \bar{p}_{0}=\frac{1+e}{\lambda-\kappa} \bar{p}_{0} d \varepsilon_{v}^{p}
$$


where $\lambda$ and $\kappa$ are the compression and swelling indices respectively. The following flow rule is employed in the model,

$$
d \varepsilon_{q}^{p}=\langle d L\rangle \frac{\partial \bar{f}}{\partial \bar{q}} \text { and } d \varepsilon_{v}^{p}=\langle d L\rangle \frac{\partial \bar{f}}{\partial \bar{q}} D
$$

where $d L$ is the loading index; \langle\rangle are the McCauley brackets. According to Eqs. (2) and (6), one has the following relations when the stress state lies on the bounding surface,

$$
d \varepsilon_{v}^{p}=\langle d L\rangle \frac{\partial \bar{f}}{\partial \bar{q}} D_{R=1}=\langle d L\rangle \frac{\partial \bar{f}}{\partial \bar{q}} \frac{\left(M_{c}^{2}-\bar{\eta}^{2}\right)}{2 \bar{\eta}}
$$

In conjunction with Eqs. (4) and (7), the condition of consistency on the bounding surface follows,

$$
\frac{\partial \bar{f}}{\partial \bar{p}} d \bar{p}+\frac{\partial \bar{f}}{\partial \bar{q}} d \bar{q}+\frac{\partial \bar{f}}{\partial \bar{p}_{0}} \frac{\partial \bar{p}_{0}}{\partial \varepsilon_{v}^{p}} d \varepsilon_{v}^{p}=\frac{\partial \bar{f}}{\partial \bar{p}} d \bar{p}+\frac{\partial \bar{f}}{\partial \bar{q}} d \bar{q}+\langle d L \underbrace{\frac{\partial \bar{f}_{p}}{\partial \bar{p}_{0}} \frac{\partial \bar{p}_{0}}{\partial \varepsilon_{v}^{p}} \frac{\partial \bar{f}}{\partial \bar{q}} \bar{D}}_{-\bar{K}_{p}}=0
$$

The plastic modulus at the image stress point, $\bar{K}_{p}$, can therefore be determined based on Eqs. (5)-(8)

$$
\bar{K}_{p}=-\frac{\partial f}{\partial \bar{p}_{0}} \frac{(1+e) \bar{p}_{0}}{(\lambda-\kappa)} D_{R=1}=-\frac{(1+e) \bar{p}_{0}}{(\lambda-\kappa)} \frac{\partial \bar{f}}{\partial \bar{p}_{0}} \frac{\partial \bar{f}}{\partial \bar{q}} \frac{\left(M_{c}^{2}-\bar{\eta}^{2}\right)}{2 \bar{\eta}}
$$

Critical to the performance of a bounding surface model is the relation between $\bar{K}_{p}$, which can describe the increase of stiffness and peak stress ratio of clay with the degree of overconsolidation, and the plastic modulus at the current stress state, $K_{p}$. In previous bounding surface models, $K_{p}$ is typically assumed to be an interpolation function of $\bar{K}_{p}$ and a shape-hardening function (Dafalias and Herrmann 1986; Ling et al. 2002) or reference modulus (Banerjee and Yousif 1986; Pestana and Whittle 1999). To avoid excessive complication, the expression for $K_{p}$ in this paper is simply assumed to be of the identical form of $\bar{K}_{p}$ by simply replacing $M_{c}$ with a virtual peak stress ratio $M_{v}$, 


$$
K_{p}=-\frac{(1+e) \bar{p}_{0}}{(\lambda-\kappa)} \frac{\partial \bar{f}}{\partial \bar{p}_{0}} \frac{\partial \bar{f}}{\partial \bar{q}} \frac{\left(M_{v}^{2}-\eta^{2}\right)}{2 \eta}
$$

where $M_{v}$ is related to $R$ according to

$$
M_{v}=M_{c} R^{-n}
$$

where $n$ is a non-negative model parameter. Since the term $-\frac{(1+e) \bar{p}_{0}}{(\lambda-\kappa)} \frac{\partial \bar{f}}{\partial \bar{p}_{0}} \frac{\partial \bar{f}}{\partial \bar{q}}$ is always positive as long as $\bar{p}>0 \quad\left(\frac{\partial \bar{f}}{\partial \bar{p}_{0}}<0\right.$ and $\left.\frac{\partial \bar{f}}{\partial \bar{q}}>0\right)$, the sign of $K_{p}$ is controlled by the term $M_{v}^{2}-\eta^{2}$. For OC clay, $K_{p}$ is dependent on the difference between the current stress ratio $\eta(=\bar{\eta})$ from the virtual peak stress ratio $M_{v}$ attainable at the current degree of overconsolidation defined by $R$. Since $R \leq 1$, the virtual peak stress ratio $M_{v}$ in Eq. (11) is a decreasing function of $R$ and thus an increasing function with the degree of overconsolidation, which is indeed supported by the experimental observations (Zervoyanis 1982; Nakai and Hinokio 2004; Mita et al., 2004). The introduction of a virtual peak stress ratio is to address the strain softening response after the peak stress ratio state of OC clay as first discussed by Wood et al. (1994). At the critical state, $R=1, M_{v}=M$ and $K_{p}=\bar{K}_{p}=0$. The same incremental elastic relation in the MCC model is followed.

\section{Model calibration and verification}

\section{Parameter determination}

There are a total of 8 parameters for the model, 5 of which are identical with those in the Cam-clay models. These parameters can be calibrated according to the following procedure.

(a) $\varphi_{c}$ is normally calibrated according to the failure stress ratio $M_{c}$ of NC clay in triaxial compression. $\lambda$ and $\kappa$ can be determined based on the isotropic consolidation/swelling or Oedometer tests on a reconstituted clay. The Poisson 
ratio $v$ (in the range of 0 to 0.5 ) controls the elastic response of clays and can be calibrated to fit the $\varepsilon_{q}\left(\varepsilon_{a}\right)-q$ relation in triaxial compression tests at small strain levels (The small strain non-linearity is not considered here), where $\varepsilon_{a}$ is the axial strain. Since the initial void ratio $e_{0}$ is also required in the model implementation, we need to determine the location of the normal consolidation line in the $e-p$ plane, or equivalently, the value of $\Gamma$, which is the void ratio at the reference pressure $p_{r}$ on the normal compression line. As the void ratio variation is not significant in most cases, the average values of $\lambda /\left(1+e_{0}\right)$ and $\kappa /\left(1+e_{0}\right)$ may also be used in the model implementation without knowing $\Gamma$ (e.g., Dafalias and Herrmann 1986; Yao et al. 2011). The other three parameters, $\alpha, m$ and $n$, can be calibrated as follows.

(b) $\alpha$ : Under undrained triaxial compression/extension loading conditions, the model gives the following relation (see the Appendix)

$$
p_{f} / p_{i}=(\mathrm{OCR} \cdot \alpha / 2)^{(\lambda-\kappa) / \lambda}
$$

where $p_{f}$ is the mean effective stress at critical state and $p_{i}$ is the initial confining pressure. Since $\lambda$ and $\kappa$ are known, $\alpha$ can be evaluated from Eq. (12) directly (The test data on NC clay is recommended as the critical state is easier to identify). Generally, it is found smaller $\alpha$ makes the soil behavior more contractive with lower peak shear strength as shown in the case for Boston blue clay (data from Pestana et al. 2002) (Fig. 4). In Fig. 4, the dash lines represent a sensitivity study of the model simulation with $\alpha=0.5$ and $\alpha=1$ for the NC clay as compared to the solid lines which stand for the model predictions with the parameters shown in Table 1. According to this trend, $\alpha$ can also be calibrated based on the drained tests (e.g., in the cases of black kaolinite clay as will be discussed below).

(c) $m$ and $n$ : These two parameters should be calibrated based on the test results on OC clay. It is observed that the variation of $m$ (typically in the range of 0-0.6 
based on our experience) does not have significant influence on the predicted $\varepsilon_{q}\left(\varepsilon_{a}\right)-q$ relations (e.g., the case for the Boston Blue Clay shown in Fig. 4). We hereby can first set $m=0$, and calibrate $n$ through fitting the $\varepsilon_{q}\left(\varepsilon_{a}\right)-q$ relation under either drained or undrained condition. Generally, greater $n$ gives stiffer response as both $M_{v}$ and $K_{p}$ are increasing functions of $n$ for $R \leq 1$ [see Eqs. (10) and (11)]. $m$ can then be calibrated by fitting the $\varepsilon_{q}-\varepsilon_{v}$ relation in drained cases (e.g., the black kaolinite case shown in Fig. 5) or the $p-q$ relation in undrained cases (e.g., the Boston blue clay shown in Fig. 4).

Table 1 Model parameters for clays

\begin{tabular}{ccccccccc}
\hline Materials & $\varphi\left(^{\circ}\right)$ & $\lambda$ & $\kappa$ & $v$ & $\Gamma\left(p_{r}(\mathrm{kPa})\right)$ & $\alpha$ & $m$ & $n$ \\
\hline Boston blue clay & 33.5 & 0.184 & 0.036 & 0.1 & $1.01(300)$ & 0.68 & 0.3 & 1.5 \\
Black kaolinite clay & 21.1 & 0.235 & 0.0827 & 0.2 & $1.298(161)$ & 1.3 & 0 & 0.5 \\
Kaolin clay & 26.3 & 0.14 & 0.05 & 0.25 & $e_{0} \approx 0.95^{\#}$ & 0.65 & 0.2 & 2 \\
\hline Typical range & & & & & & 0.65 & 0 & 0.5 \\
& & & & & & $\sim 1.3$ & $\sim 0.6$ & $\sim 2$ \\
\hline
\end{tabular}

\section{Model verification}

The dilatancy relation and the bounding surface modeling have been verified on a total of 3 different OC clays, including the Boston blue clay (data from Pestana et al., 2002), the black kaolinite clay (Zervoyanis 1982) and the kaolin clay (Stipho 1978). The model parameters are determined according to the procedure outlined in the last subsection. Their final values and typical range are summarized in Table 1. Furthermore, it is instructive to explain the details on model parameter determination for the three clays to be treated in the study:

(a) Boston blue clay: The five parameters inherited from the Cam-Clay models $(\varphi, \lambda, \kappa, v$ and $\Gamma)$ are directly obtained from the literature (see, e.g., Pestana et al., 2002). $\alpha$ is calculated using Eq. (12) based on the effective stress path for normally consolidated samples. $n$ is then determined by 
fitting the $\varepsilon_{a}-q$ relations for the overconsolidated samples shown in Fig. 4a by imposing $m=0$. Finally, $m$ is obtained to fit the effective stress paths for overconsolidated samples by keeping the other parameters at their determined values.

(b) Black kaolinite clay: The parameters inherited from the Cam-Clay models $(\varphi, \lambda, \kappa, v$ and $\Gamma)$ are obtained according to Yin et al. (2013). Since there is no undrained test data available for this soil, Eq. (12) cannot be used to determine $\alpha$. Thus, $\alpha$ is determined by fitting the $\varepsilon_{a}-q$ and $\varepsilon_{a}-e$ relations for the normally consolidated sample. $n$ is then determined by fitting the $\varepsilon_{a}-q$ relations for overconsolidated samples in Fig. 5a by keeping $m=0$. Finally, $m$ is obtained to best fit the $\varepsilon_{a}-e$ relations for the overconsolidated samples while keeping the other parameters unchanged.

(c) Kaolin clay: The parameters inherited from the Cam-Clay models $(\varphi, \lambda, \kappa, \nu$ and $\Gamma$ ) are obtained according to Banerjee and Yousif (1986). The rest of the parameters are determined following the same procedure for the Boston blue clay.

The model predictions are comparatively presented in Figs. 4-6 with test results on these clays. From Figs. 4-6, good comparison can be found between our model predictions with the test data on the Boston blue clay (data from Pestana et al. 2002), the black kaolinite clay (Zervoyanis 1982) and the kaolin clay (Stipho 1978). In particular, in the case of black kaolinite clay, the proposed dilatancy relation in Equation (2) is shown to offer very good predictions on the trend of dilatancy change with OCR as compared to the test data (see Fig. 5b). Meanwhile it is noticed that the model slightly over-predicts the undrained shear strength of kaolin clay at low OCR to NC range, but provides faithful predictions for the middle to high OCR cases (Fig. 6). Since the model parameters are considered to be inherent material parameters, $m$ and $n$ have been determined to best fit an entire group of test results over a range of 
OCRs rather than for a single OCR. As a result, the model predictions may appear to be good for some OCRs but less satisfactory for some others.

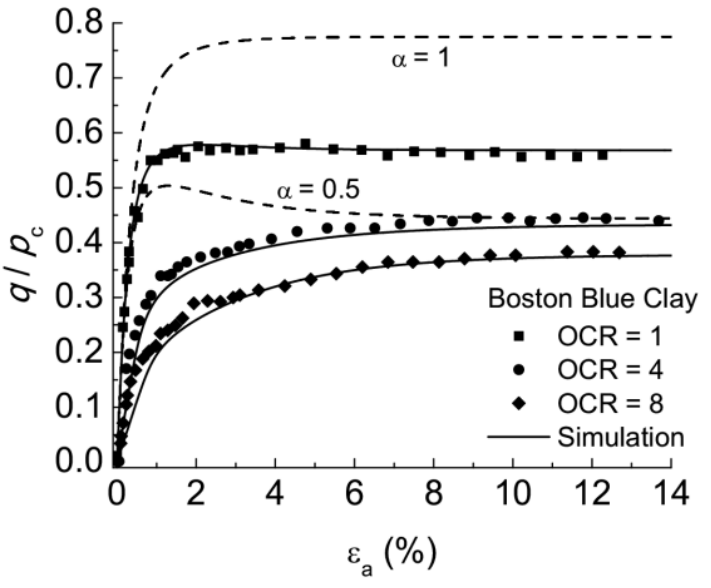

(a)

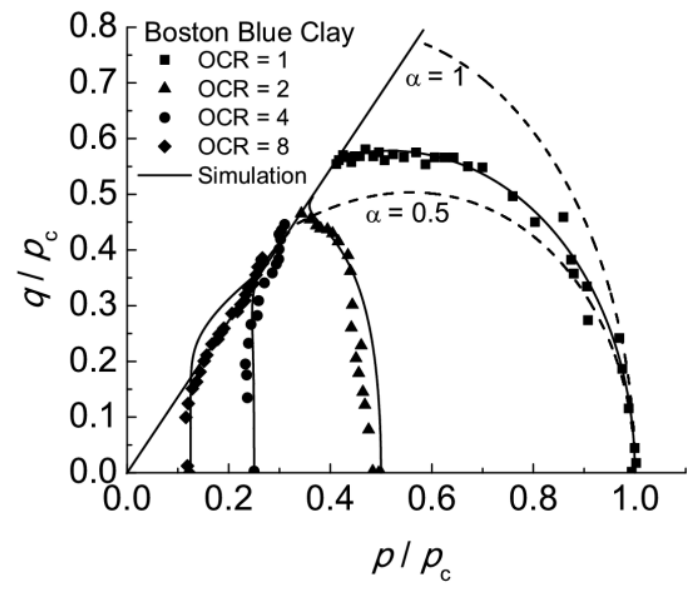

(b)

Fig. 4 Comparison between the model simulation and test results on Boston blue clay [data from Pestana et al. (2002)] as well as the parametric study results for $\alpha$ in NC case: (a) the $\varepsilon_{a}-q / p_{c}$ relations and (b) the effective stress paths

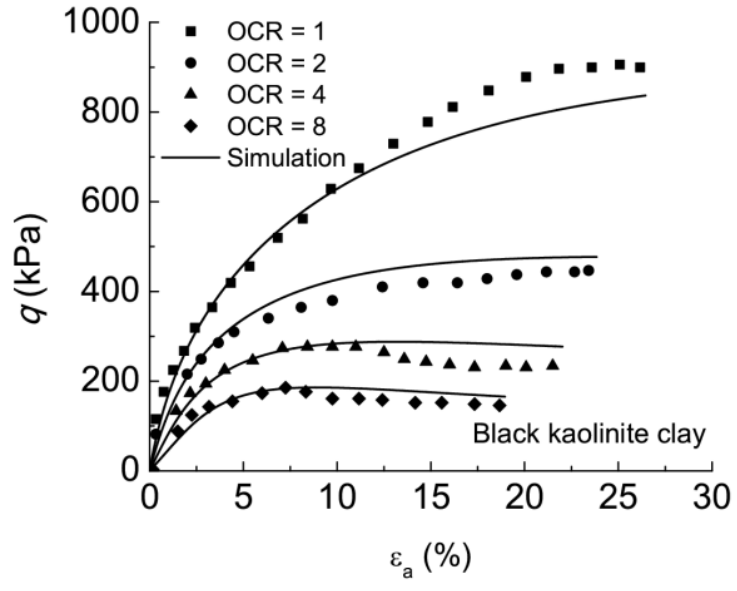

(a)

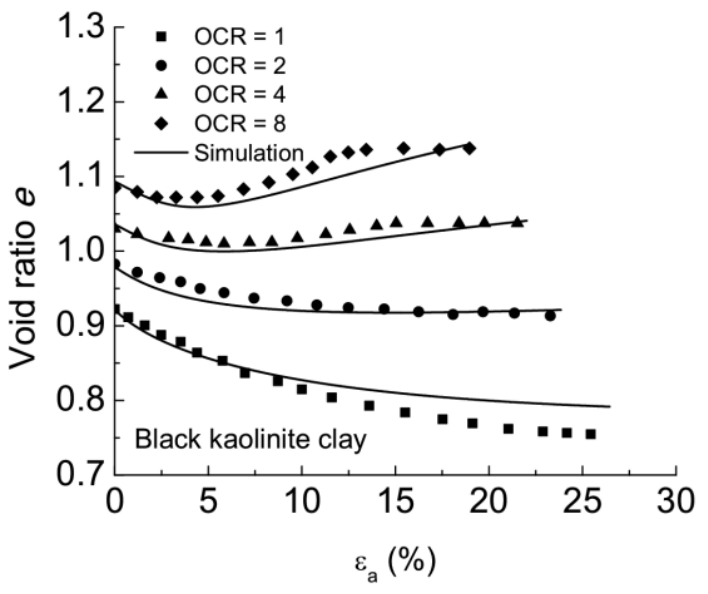

(b)

Fig. 5 Model simulations for the behavior of black kaolinite clay in drained triaxial compression [tests by Zervoyanis (1982) \& $p_{c}=800 \mathrm{kPa}$ ] (a) the $\varepsilon_{a}-q$ relations and (b) the $\varepsilon_{a}-e$ relations. 


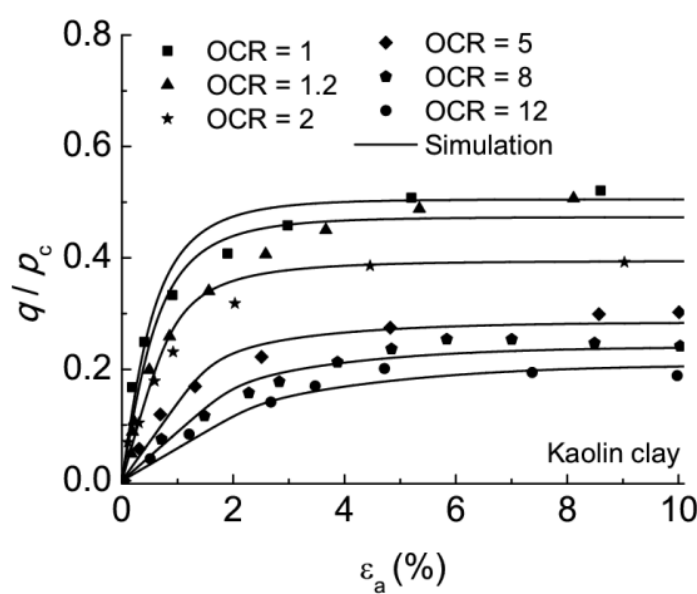

(a)

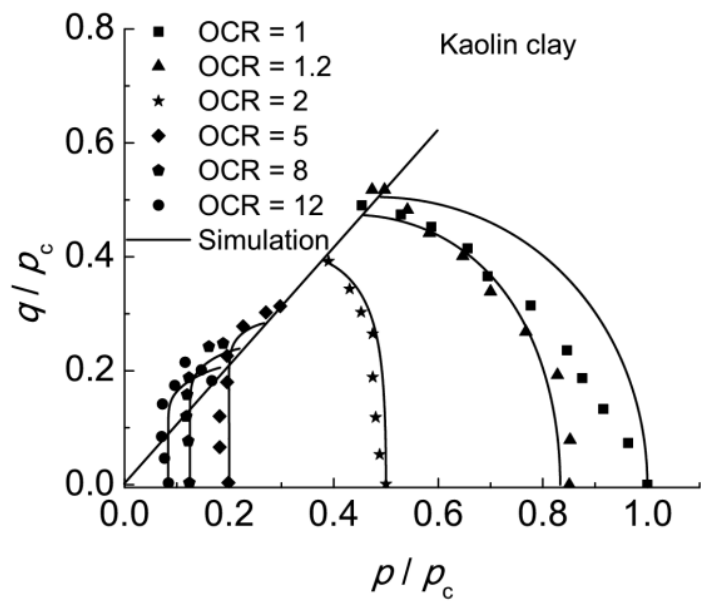

(b)

Fig. 6 Model simulations for the behavior of kaolin clay in undrained triaxial compression [tests by Stipho (1978) and data from Ling et al. (2002)]: (a) the $\varepsilon_{a}-q / p_{c}$ relations and (b) the effective stress paths.

\section{Conclusion}

Dilatancy of clay is closely related to the degree of overconsolidation. Their inter-correlation should be properly considered in constitutive modelling for clays. A simple dilatancy relation accounting for the influence of overconsolidation in clay has been proposed in this study. This relation can be readily implemented in a bounding/subloading surface model. As an illustrative example, a predictive bounding surface model for OC clay has been proposed based on this dilatancy relation. The model includes 3 extra parameters in addition to the original five in the Cam-clay model, all of which can be conveniently determined according to routine laboratory test results on $\mathrm{NC}$ and $\mathrm{OC}$ clays under either drained or undrained triaxial compression conditions. Detailed procedures for determining these model parameters have been provided. The model has been demonstrated to perform reasonably well in predicting the behavior of three clays as compared to their test data.

Indeed, the proposed dilatancy relation is generic and can be easily implemented in any other bounding/subolading surface models for clays if overconsolidation is of a 
concern. In its present form, however, the dilatancy relation is unable to account for the influence of anisotropy on the mechanical behavior of clays (e.g., Ling et al. 2002; Anandarajah and Dafalias 1986; Dafalias et al. 2006). Its extension to account for anisotropy may be possibly made in conjunction with the recent progresses on anisotropic critical state theory (Li and Dafalias, 2012; Gao et al., 2014; Gao and Zhao, 2015; Zhao and Gao, 2016), which will be a future pursuit of the authors'. In addition, the dilatancy of clay in cyclic loading has been found dependent not only on the degree of overconsolidation but also shear strain accumulation (e.g., Ni et al., 2014; Kimoto et al., 2014). Substantial modifications may be required if the dilatancy relation is to be used to address the cyclic response of clay. Lastly, if a subloading surface or bounding surface model implemented with the dilatancy relation is used to treat a boundary value problem, great care need to be paid pertaining to its numerical implementation (e.g., via finite elements) as it is a well-known challenge for such a complex soil model. In this regard, the explicit stress integration method with automatic error control (Sloan et al., 2001) has been found effective for implementing complex bounding/subloading surface models (Gao and Zhao, 2013; Zhao et al., 2005) and can be used for the implementation.

\section{Appendix: Relation between $p_{f}$ and $p_{i}$}

The relation between $p_{f}$ and $p_{i}$ can be derived based on Fig. C1 shown below. Points B and C denote the initial and final states of the sample in Fig. C1. The void ratio at Point $\mathrm{B}\left(e_{B}\right)$ is

$$
e_{B}=e_{A}+\kappa \ln \left(\frac{p_{c}}{p_{i}}\right)=e_{A}+\kappa \ln (\mathrm{OCR})
$$

where $e_{A}$ is the void ratio at Point A.

The void ratio at Point $\mathrm{C}\left(e_{C}\right)$ is

$$
e_{C}=e_{A}+\kappa \ln \left(\frac{p_{c}}{p_{x}}\right)-\lambda \ln \left(\frac{p_{f}}{p_{x}}\right)
$$


Since $p_{x}=\frac{\alpha}{2} p_{c}=\frac{\alpha}{2} p_{i} \cdot$ OCR, one can get the following relation based on Eq. (C.2)

$$
e_{C}=e_{A}+\kappa \ln \left(\frac{2}{\alpha}\right)-\lambda \ln \left(\frac{2 p_{f}}{\alpha p_{i} \cdot \mathrm{OCR}}\right)
$$

Since the void ratio of the sample keeps constant in undrained loading, $e_{C}=e_{B}$. Thus, the relation between $p_{f}$ and $p_{i}$ can be obtained based on Eqs. (C.1) and (C.3) as below

$$
p_{f} / p_{i}=(\mathrm{OCR} \cdot \alpha / 2)^{(\lambda-\kappa) / \lambda}
$$

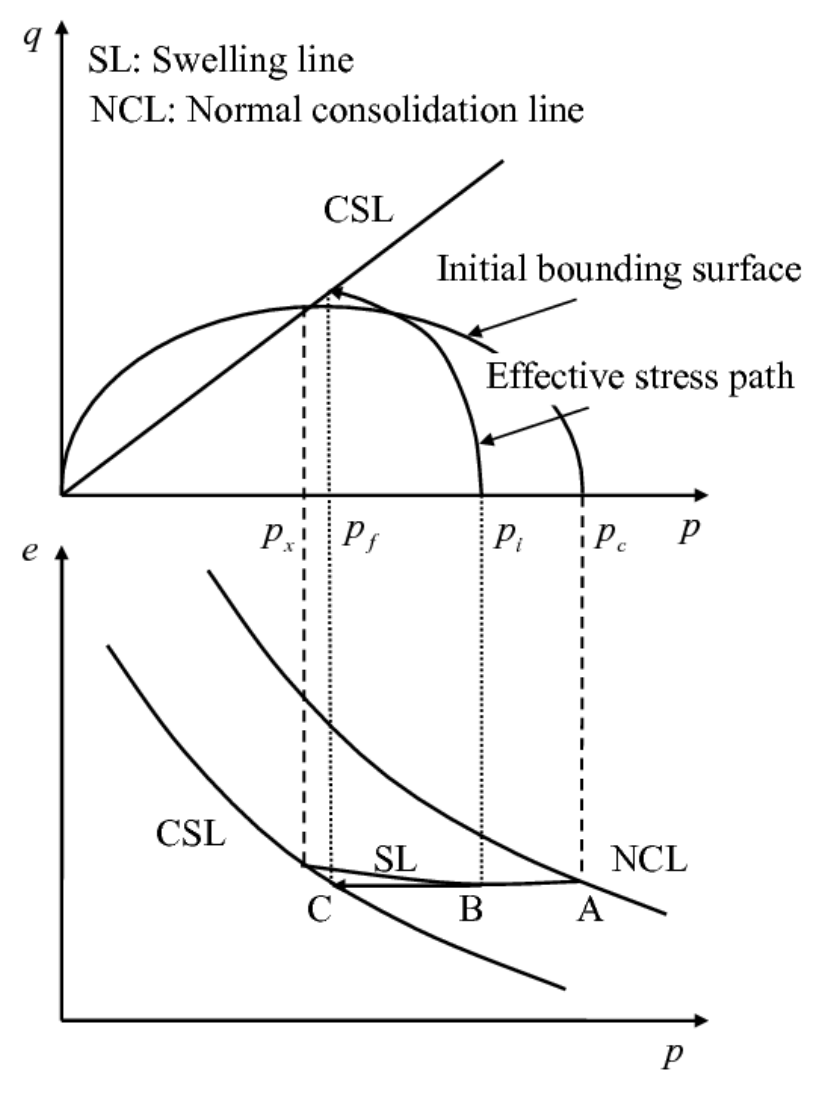

Fig. C1 Relation between $p_{f}$ and $p_{i}$ in undrained triaxial compression test

\section{Acknowledgement}

This work was supported by Research Grants Council of Hong Kong (under grant no. 623211 and SBI08/09.EG02). The second author also would like to acknowledge the financial support from Innovate UK and QTS Group Ltd. through a Knowledge Transfer Project (Project No. KTP 9880). 


\section{Reference}

Banerjee, P. K., and Yousif, N. B. (1986). "A plasticity model for the mechanical behavior of anisotropically consolidated clay." Int. J. Numer. Anal. Meth. Geomech., 10, 521-541.

Been, K., and Jefferies, M. G., (1985). “A state parameter of sands.” Géotechnique, $35(2), 99-112$.

Bolton, M. D. (1986). "The strength and dilatancy of sands.” Géotechnique, 36(1), $65-78$.

Collins, I. F., and Muhunthan, B. (2003). "On the relationship between stress-dilatancy, anisotropy, and plastic dissipation for granular materials." Géotechnique, 53(7), 611-618.

Collins, I. F., (2005). "Elastic/plastic models for soils and sands." Int. J. Mech. Sci., 47, 493-508.

Dafalias, Y. F. (1986). "Bounding surface plasticity I: Mathematical formulation and hypoplasticity.” J. Eng. Mech., 112(9), 966-987.

Dafalias, Y. F., and Herrmann, L.R. (1986). "Bounding surface plasticity II: Application to isotropic cohesive soils.” J. Eng. Mech., 112(12), 1263-1291.

Dafalias, Y. F., Manzari, M.T., and Papadimitriou, A.G. (2006). "SANICLAY: simple anisotropic clay plasticity model." Int. J. Numer. Anal. Meth. Geomech., 30, $1231-1257$

Gao, Z.W., Zhao, J.D., Li, X.S., Dafalias, Y.F. (2014). A Critical State Sand Plasticity Model Accounting for Fabric Evolution. Int. J. Numer. Anal. Meth. Geomech., 38(4), 370-390.

Gao, Z., and Zhao, J. (2013). "Strain Localization and Fabric Evolution in Sand." Int. J. Solids. Struct. 50, 3634-3648.

Gao, Z. and Zhao, J. (2015). "Constitutive Modeling of Anisotropic Sand Behavior in Monotonic and Cyclic Loading." J. Eng. Mech., 141(8), 04015017.

Gens, A. (1982). "Stress-strain and strength of a low plasticity clay." Ph.D. Thesis at Imperial College, London University.

Hashiguchi, K. (1980). "Constitutive equations of elastoplastic materials with 
elastic-plastic transition.” J. Appl. Mech., 47, 266-272.

Hattab, M., and Hicher, P.Y. (2004). "Dilating behavior of overconsolidated clay." Soils Found., 44(4), 27-40.

Henkel, D. J. (1956). "The effect of overconsolidation on the behaviour of clays during shear." Géotechnique, 6(4), 139 -150.

Herrmann, L. R., Shen, C. K., Jafroudi, S., DeNatale J. S., and Dafalias, Y. F. (1981). "A verification study for the bounding surface plasticity model for cohesive soils." Final Report to Civil Engineering Laboratory, Naval Construction Center, Port Hueneme, Calif., Order No. USN N62583-81 M R320.

Jefferies, M. G. Shuttle, D. A. (2002). "Dilatancy in general Cambridge-type models." Géotechnique, 52(9), 625-638.

Jiang, J., and Ling, H. I. (2010). ”A framework of an anisotropic elastoplastic model for clays.” Mech. Res. Commun., 37, 394-398.

Kimoto, S., Shahbodagh Khan, B., Mirjalili, M., and Oka, F. (2014). "Cyclic Elastoviscoplastic Constitutive Model for Clay Considering Nonlinear Kinematic Hardening Rules and Structural Degradation." Int. J. Geomech., 15(5), A4014005.

Li, X. S., and Dafalias, Y. F. (2000). "Dilatancy for cohesionless soils.” Geotechnique, 50(4), 449-460.

Li, X. and Dafalias, Y. (2012). "Anisotropic Critical State Theory: Role of Fabric." J. Eng. Mech., 138(3), 263-275.

Ling, H. I., Yue, D. Y., Kaliakin, V. N., and Themelis, N. J. (2002). “Anisotropic elastoplastic bounding surface model for cohesive soils.” J. Eng. Mech., 128(7), 748-758.

Mita, K., Dasari, G., and Lo, K. (2004). "Performance of a Three-Dimensional Hvorslev-Modified Cam Clay Model for Overconsolidated Clay.” Int. J. Geomech., 4(4), 296-309.

Nakai, T., and Hinokio, M. (2004). "A simple elastoplastic model for normally and over-consolidated soils with unified material parameters." Soils Found., 44(2), 53-70.

Ni, J., Indraratna, B., Geng, X., Carter, J., and Chen, Y. (2014). "Model of Soft Soils 
under Cyclic Loading." Int. J. Geomech., 15(4), 04014067.

Pestana, J. M., and Whittle, A. J. (1999). "Formulation of a unified constitutive model for clays and sands.” Int. J. Numer. Anal. Meth.Geomech., 23, 1215-1243.

Pestana, J. M., Whittle, A. J., and Gens, A. (2002). "Evaluation of a constitutive model for clays and sands: Part II - clay behaviour." Int. J. Numer. Anal. Meth. Geomech., 26, 1123-1146.

Roscoe, K. H., and Burland, J. B. (1968). “On the generalized stressstrainbehavior of 'wet' clay.” In: Heyman, J., Leckie, F.A. (Eds.), Engineering plasticity, Cambridge University Press, 535-609.

Roscoe, K. H., and Schofield, A. N. (1963). "Mechanical behaviour of an idealized 'wet' clay.” Proc. Eur. Conf. Soil Mech. Found. Engng, Wiesbaden, 1, 47-54.

Rowe, P. W. (1962). "The stress-dilatancy relation for static equilibrium of an assembly of particles in contact." Proc. Roy. Soc. London., A269, 500-527.

Scarpelli, G., Sakellariadi, E., and Fruzzetti, V. M. E. (2003). "The dilatant behaviour of overconsolidated clays." Proceedings of the third International Symposium on Deformation Characteristics of Geomaterials, 451-459.

Schofield, A. N. (1998). "The Mohr-Coulomb error.” Proc. Symp. On Mechanics and Geotechnics, LMS Ecole Polytechnique, Paris, 23, 19-27.

Shimizu, M. (1982). "Effect of overconsolidation on dilatancy of a cohesive soil." Soils Found., 22(4), 121-135.

Sloan, S. W., Abbo, A. J., and Sheng, D. (2001). "Refined explicit integration of elastoplastic models with automatic error control.” Eng. Comput. 18, 121-154.

Stipho, A. S. A. (1978). "Experimental and theoretical investigation of the behavior of anisotropically consolidated kaolin.” PhD thesis, Univ. College, Cardiff, U.K.

Taylor, D. W. (1948). Fundamentals of soil mechanics. Wiley, New York.

Wood, M. D., Belkheir, K., and Liu, D. F. (1994). "Strain softening and state parameter for sand modelling." Géotechnique, 44(2), 335-339.

Yao, Y. P., Gao, Z. W., Zhao, J. D., and Wan, Z. (2011). "Modified UH model: constitutive modeling of overconsolidated clays based on a parabolic Hvorslev envelope." J. Geotech. Geoenviron. Eng., 138(7), 860-868. 
Yao, Y. P., Hou, W., and Zhou, A. N. (2009). "UH model: three-dimensional unified hardening model for overconsolidated clays." Géotechnique, 59(5), 451-469.

Yin Z. Y., and Chang, C. S. (2009). "Non-uniqueness of critical state line in compression and extension conditions." Int. J. Numer. Anal. Meth. Geomech., 33, $1315-1338$.

Yin, Z. Y., and Chang, C. S. (2013). "Stress-dilatancy behavior for sand under loading and unloading conditions.” Int. J. Numer. Anal. Meth. Geomech., 37(8), 855-870.

Yin, Z. Y., Xu, Q., and Hicher, P. Y. (2013). "A simple critical state based double-yield-surface model for clay behavior under complex loading." Acta Geotechnica, 8(5), 509-523.

Yin, J. H., Zhu, J. G., and Graham, J. (2002). "A new elastic viscoplastic model for timedependent behaviour of normally and overconsolidated clays: theory and verification." Can. Gotech. J., 39, 157-173.

Zervoyanis, C. (1982). Etude synthétique des propriétés mécaniques des argiles et des sables sur chemin oedométrique et triaxial de revolution. Thèse de Docteur-Ingénieur, Ecole Centrale de Paris (in French).

Zhao, J. and Gao, Z. (2016). "Unified Anisotropic Elastoplastic Model for Sand." J. Eng. Mech., 142(1), 04015056.

Zhao, J., Sheng, D., Rouainia, M., and Sloan, S.W. (2005). Explicit stress integration of complex soil models." Int. J. Numer. Anal. Meth. Geomech., 29(12), 1209-1229. 